\title{
Prospective Teachers from Urban Environments Examine Causes of the Achievement Gap in the United States
}

\author{
Erik E. Morales ${ }^{1}, \mathrm{PhD}$, Professor/Chair \\ ${ }^{1}$ Dept. of Elementary \& Secondary Education, Professional Build. Rm. 329, College of Education, New Jersey City \\ University, Jersey City, NJ 07305-1597, USA \\ Correspondence: Erik E. Morales, PhD, Professor/Chair, Dept. of Elementary \& Secondary Education, Professional \\ Build. Rm. 329, College of Education, New Jersey City University, Jersey City, NJ 07305-1597, USA
}

Received: February 15, 2016

Accepted: March 6, 2016

Online Published: March 15, 2016

doi:10.5430/ijhe.v5n2p101

URL: http://dx.doi.org/10.5430/ijhe.v5n2p101

\begin{abstract}
This study analyzes the educational achievement gap between low and high socioeconomic students from the perspective of sixty-two prospective teachers in an undergraduate educational foundations course at a public majority minority urban university in the northeastern United States. The majority of these college students come from, and plan to teach in, lower socioeconomic areas; consequently their insights are uniquely relevant. These prospective teachers cite the following as key causes of the achievement gap: lack of parental involvement, linguistic conflicts between home and school, a lack of bicultural teachers, and the perception of anti-intellectual k-12 school climates. Implications of how these views may affect these prospective teachers when they enter the teaching profession are addressed.
\end{abstract}

Keywords: Achievement Gap, Teacher Preparation, Urban Teaching

\section{Introduction}

The most discussed and deliberated concept in current educational discourse is the achievement gap that continues to persist between low (disproportionally children of color) and high (disproportionally Caucasian) socioeconomic students (Hattie, 2009; Matthew, 2014). Its importance is based in large part on the fact that college degree attainment remains the most direct and common route to middle class status for those from low socio-economic backgrounds (Haskins \& Rouse, 2013; Perna, 2005). Furthermore, increasing the numbers of these students earning degrees has residual positive effects; including increased employment and global competitiveness, decreased incarceration, and less reliance on government assistance. Understanding and improving the path towards college attainment for those least likely to excel has even taken on a moral facet. Given the United States' history of discrimination and both de jure and de facto segregation, it has been persuasively argued that the narrowing of the achievement gap is in essence a pressing "social justice" issue (Collopy, Bowman, \& Taylor, 2012; Ladson-Billings, 2006), requiring educators to look at teacher dispositions and views toward equity and fairness as a means of amelioration (Borrero, 2011; Brown, 2010; Villegas, 2007).

There is some new data showing that all students, and particularity black and Hispanic students, are gradually improving academically, thus narrowing the gap slightly (Leyton, 2013). However, major gaps remain. Recent data indicate that on average only 56 percent of students beginning college any given fall will earn their degrees within six years (NCES, 2013). When disaggregating persistence percentages for students from ethnic minority groups, whose members are significantly more likely to be low socioeconomic and first-generation college students, the percentages are telling. For white students the six year college graduation rate was almost 60 percent, for black students it was 35 percent, and for Hispanics 47 percent (NCES, 2013). Furthermore, data also find substantive gaps in high school completion, SAT/ACT scores, and college admission (Hattie, 2009). Untimely, researchers and practitioners acknowledge the pressing need to take action and address these longstanding issues (Regan, Berkeley, \& Ray, 2013). On a truly level playing field the ethnicity and socioeconomic status of one's parents would not be such strong indicators of ultimate academic and, by extension, social outcomes.

\section{A Critical Perspective Missing}

The achievement gap issue has been explored from a variety of angles, though mostly from the viewpoints of educational policy analysts, researchers, and political entities. Consequently, one fascinating and critical perspective 
is often missing- that of the soon to be teacher who hails from the very same environments that so often fail our lower socioeconomic children (Collopy, Bowman, \& Taylor, 2012; Gomez \& Rodriguez, 2011).

The potential significance of revealing and documenting this perspective is threefold:

- One, these individuals were born and raised in lower socioeconomic urban environments; consequently, their views on their backgrounds and the achievement gap contain unique relevance, veracity, and potential applicability.

- Two, these individuals are poised to enter the K-12 teaching field themselves, often teaching in the very environments from which they have come. Their views are not of solely theoretical import, but have the potential to directly impact the achievement gap.

- Three, these individuals are uniquely positioned to combine an intimate and direct understanding of the realities of urban schools and communities with the theoretical and sociological concepts they have been learning in college. Consequently, their insights are not only authentic and insightful, but also relatively sophisticated and well-informed.

While it can be exceedingly difficult to ascertain exactly how college classroom experiences specifically impact what teachers do once they enter the field (Halai, 2004), the entire system of teacher education is based on the premise that there is a direct connection between what and how prospective teachers learn and how they will teach.

As a theoretical framework, essentially the college students in this research study are engaged in "transformative learning." "Transformative learning" refers to a process of learning whereby individuals acknowledge relevant prior experiences, articulate belief systems, and are open to reformulate their beliefs if and when exposed to persuasive conflicting data or experiences (Mezirow, 2000). The concept of transformative learning will be the lens through which the participating students' evolving beliefs regarding the achievement gap will be viewed and documented.

Importantly, the sorts of critical thinking exercises and experiences which characterize quality college classrooms help students engage in the sort of profound and meaningful learning. The ability to engage in transformative learning is especially valuable for prospective teachers entering urban environments given the documented need to reflect upon and address their own preconceptions (Morrison, 2014: Roselle \& Liner, 2012; Stairs, 2008).

Understanding and facilitating quality teachers willing and able to work effectively in urban areas is further justified by the fact that that statistically speaking students of color from low socioeconomic areas overwhelmingly attend segregated schools and have less qualified and less experienced teachers (Gagnona \& Mattinglya, 2015). As Darling-Hammond (2010) articulates "Frequently, in the growing number of apartheid schools serving more than 90 percent of students of color, a majority of teachers are inexperienced and uncertified" (p. 3). The reality that very often the most needy schools and students have the least experienced and accomplished teachers helps reinforce and perpetuate the social reproduction which often characterizes individuals from lower socioeconomic environments, and contributes to recurring cycles of poverty and underemployment.

While there are many factors cited as contributing to the achievement gap, and a major one is the relative lack of teachers of color in public schools nationwide (Gay, Dingus \& Jackson, 2003; Hurtado, 1996; Morrison, 2009). Of all teachers in the United States, only fifteen percent are "non-white" (Morrison, 2009), whereas the percentage of non-white students in public schools is now over fifty (NCES, 2014). Additionally, while most teachers come from middleclass backgrounds, currently one in three children are being raised in poverty (Ingraham, 2014). Researchers have long acknowledged that because the backgrounds of most teachers (white, monolingual, and female) are significantly different than most of their students, a problematic "cultural discontinuity" can arise (Banks, 1991; Delpit, 2006; Goldenberg, 2014; Howard, 1999; Lawrence, 1997; Williams, 2013). Cultural discontinuity refers to a sociocultural phenomenon where the cultural background of the students conflicts with the cultural values of their teachers and schools. This mismatch can often result in lower achievement for students from diverse backgrounds. This is not to say that shared ethnicity among student and teacher is a prerequisite for academic success, only that evidence does exist that it can help significantly (Delpit, 2006; Landis, Ferguson, Carballal, Kuhlman \& Squires, 2007). Finally, increasing the number of culturally diverse teachers can decrease the degree to which teachers view urban students and schools as pathological problems to be solved as opposed to communities with which to engage and support (Matias \& Liou, 2015).

Given their relative scarcity, as well as their unique experiences and potential to impact K-12 schooling, future educators from lower socioeconomic backgrounds can offer unique and valuable contributions toward better understandings and addressing the achievement gap (Merseth, Sommer, \& Dickstein, 2008). 


\section{Potential Causes of the Achievement Gap}

While a thorough review of all the myriad causes of the academic achievement gap is beyond the scope of this article, an overview of major categories of causes can help lend context to the findings.

As per Haycock (2001), the causes of the achievement gap can be couched into two categories: one, what goes on in school, and two, what goes on outside of school. Commonly sighted contributors from outside the classroom include single parent households, effects of low socioeconomic status, higher rates of neighborhood violence, increased levels of stress, and lower levels of cultural and social capital (Author \& Trotman, 2011; Smith, 2008). These are often contrasted with potential in-school culprits, such as teachers' lower expectations, teacher biases, nonchallenging and non-relevant curricula, teachers with less experience, and inadequate funding (Gardner, 2007).

Consensus can also be found in acknowledging that the first category- what goes on in school, bleeds into the second- what goes on outside of school. Most would also agree that to varying extents both categories generate significant contributions to the achievement gap. Interestingly, those discussing and contemplating the achievement gap, often based on political affiliation or dogma, tend to place more responsibility on one side over the other. This placement can be significant. For classroom teachers in particular, where they place responsibility can be a critical indicator as to how they will relate to their students in the classroom.

\section{Research Objective}

The primary objective of the research was to capture the views, understandings, and attitudes of a group of predominately ethnic minority and lower socioeconomic college students planning on entering the teaching field on the following question: Who/what is responsible for the academic achievement gap between lower and higher socioeconomic students in the United States?

Using this central question these individuals' personal landscapes regarding teaching and learning in urban areas were revealed and analyzed. Additionally, action research projects such as this one have often had the additional positive effect of helping the instructor reflect upon and improve upon his/her teaching (Schratz, 1993).

\section{Research Method}

The observations and conclusions included in this study are based upon original research conducted on a total of sixty-two college students enrolled across three separate sections of an educational foundations course focused on urban schooling at a majority minority public urban university located in the northeast United States. It was made clear to students that use of their academic work for the purposes of this research was completely voluntary and that their participation, or lack thereof, would have no impact whatsoever on their course grades. All aspects of the research were reviewed and approved by the institution's IRB (Institutional Review Board).

A major topic of the course was potential reasons/causes of the achievement gap, thus the study data came mostly from three different aspects of the class: an autobiography/community study the students conducted exploring their educational backgrounds and the demographics of the schools/communities in which they were taught and raised; an analysis students wrote based on their observations of four K-12 classroom lessons conducted in local urban schools; and summaries of written and oral responses to key questions and course readings focused on achievement gap issues.

Qualitative research methodology was used to examine data from these three sources and uncover salient themes and sub-themes. This approach was selected given the efficacy of this type of research to uncover complex and nuanced feelings about personal, complicated, and multifaceted issues (McCracken, 1998; Spradley, 1979; Rubin \& Rubin, 1995; Watson \& Watson-Franke, 1985). Each participant signed a voluntary Agreement to Participate form, and filled out a Demographic Data form which documented their age, gender, ethnicity, socioeconomic status, and future employment goals.

In conducting this research data collection and analysis were distinct processes that were closely intertwined. As more and more data became available they were continually analyzed. Consistent with the qualitative research norms (Lincoln \& Guba, 1985; Rubin \& Rubin, 1995) these two activities were done continuously until "data saturation" was achieved. Data saturation is the point at which the researcher is confident that conclusions are valid and complete, and that no new data are necessary. Throughout the actual data analysis process, and in accordance with the work of Bogdan \& Biklen (1982), the researcher created coding categories and concepts, and identified emerging themes. While the primary methodology was qualitative in nature, given the significant overall sample size, some basic quantitative conclusions are presented and utilized to add further meaning and context. 


\section{Research Sample}

The sample for this study consists of sixty-two undergraduate students. Forty-one were females and twenty-one males. In terms of ethnicity, twenty-six self-identified as "Hispanic/Latino," nineteen as "White," thirteen as African-American/Black, two as "Asian-American," and two as "Middle-Eastern." Fifty-two were born in the United States (including four in Puerto Rico), and ten were born outside of the United States. In terms of socioeconomic status (SES), forty-eight identified as "lower" and "working class," and sixteen as "middle class." Fifty-two did not have a parent with a college degree, while ten did. Consequently, the population is mostly female $(66 \%)$, overwhelmingly ethnic minority (almost $70 \%$ ) and lower/working class (77\%). They are also predominantly first-generation college students (83\%), and mostly born in the United States (81\%). Finally, when asked where they planned on teaching, 53/62 (85\%) indicated they planned on teaching in urban or semi-urban k-12 school environments.

\section{Trustworthiness}

For the qualitative researcher, trustworthiness refers to assurance that the research activities are instituted properly, and that the conclusions represent as closely as reasonably possible the experiences of the individuals being studied (Ely, 1991). Furthermore, consistent with Bogdan and Biklin (1982), a variety of methods were used to promote trustworthiness, including: triangulation (using various pieces of the data to support a claim), peer de-briefing (having a colleague review some raw data and comparing findings), and member checking (rechecking with participants to ensure accurate representation of their views). All of these tools were utilized to maximize the degree of accuracy presented in the study.

\section{Findings}

\subsection{Themes}

In reviewing the data the following four broad themes emerged: 1. Role of Parents; 2. Home Language/School Language; 3. Bicultural Teachers; and 4. Anti-Intellectualism in schools. Each is explored, analyzed, and substantiated through the words of the college students/participants.

\section{Theme 1. The Roles of Parents}

Among these future teachers, there was perhaps no area as controversial, contentious, and polarizing as the low Socio Economic Status parents' possible role in the disproportionately lower academic performance of their children. It should be noted that eighteen of the sixty two students were parents themselves, and thus the issue was particularly personal for them.

Most of the students 54/62 pointed out that there were many things that low SES parents could and should be doing to help prepare their children perform better in school. The most common being: reading to children (in English at a young age), providing accountability for their homework (and helping when necessary), attending school related events, and providing intellectually stimulating home environments/experiences. Three students even argued that parents should take mandatory parenting classes in order to be eligible for free or reduced price lunches.

One of the study participants, 'Susan' (all names used are pseudonyms), discusses below what she thinks low SES parents need to be doing to help their children succeed. Her view sums up the majority of the students' views on parenting and promoting achievement.

"Like we talked about in class, we know there are certain things that usually work, that parents should be doing...they (the parents) need to make school more of a priority, to make sure the kids get their homework done, to be involved with the school and teachers, to do stuff with kids that will help them in school. Activities like reading to children and helping with homework and exposing them to culture... These are all keys that parents can and should be doing so their kids can be successful in school and life." (Susan 23, African American female)

There was a general consensus as to what parents should be doing with their children in relations to schooling, but the question of whether or not these expectations are realistic or fair, and the degree to which schools should be held more responsible for facilitating them, initiated much more disagreement.

Sandra's comments about economic and social realities captured a majority of the students' views:

"Of course it's easy to say that parents, or really mothers because there are so many single moms raising families, should be doing this and that, but I don't think it's fair to lay it on them. We learned in class that poor people tend to work hard, more hours and more jobs, than others. How can we expect them to have the 
time and energy to do all of the other stuff? You can't really expect the same things from a working single mom that you can from a stay at home mom from the suburbs. My mother gets paid by the hour, if she doesn't work she don't get paid. Can we expect her to take a half or full day off to go to a back to school night or conference? That's money she needs to pay rent and buy groceries.

(Sandra, 20, Hispanic female)

Responding to the validity of both Susan and Sondra's views, the students tackled the following question which was part of an in class writing assignment:

Who should be held more responsible for student academic achievement, parents or schools?

While virtually every student acknowledged that both parties are responsible, there was a good deal of differing opinions in regard to degrees of responsibility. The students broke down almost equally into three camps. A little more than $1 / 3$ thought it was mostly the school's responsibility, a little less than $1 / 3$ argued for parents, and the remainder saw it as a fifty-fifty proposition.

Jason's passionate exhortation for schools to do more does a good job of representing those students who believed that children's academic progress is ultimately a school responsibility.

"As educators, we are choosing to take on the responsibility of teaching whatever students are in our classrooms, nobody is forcing us to do it, it is a choice. Schools, principals, and teachers are all there for one purpose, to help students learn. We spend a lot of money on education, more than any other country, so there should be no excuses. So if they are not doing as good as they should, then we need to do more, get creative, to figure out what works. If we can't or there is too much bureaucracy then that is our fault. .....we learned about schools that do work and we learned about academic resilience, we just need to figure out how to recreate what works on a bigger scale. We may have to get more creative, find out what parents need from us, and help them get it. (Jason, 24, African American male)

Other students took a very different view. While acknowledging that there is much more schools can and should be doing, they focused more on the enormity of the challenges that poverty creates for children, and questioned if and how schools could adequately mitigate them.

Jennifer's call to be realistic is illustrative of such views:

"I don't think it's fair or realistic to think that a few hours a day for only half the year can actually fix all of the problems that some students come to school with. Maybe if the school day was longer or the year was more than 180 days, but even then it would be hard. I mean if a kid doesn't eat enough or is raised in violence and neglect from a young age, what can we expect schools to do? The fourth grade class I observed had 32 students in it and only one teacher. What is she supposed to do with a kid with severe anger problems or one who has been in foster care from a young age?.. I mean of course you try and do what you can, but realistically it's the parents who are much more in control, that's why I think they have to do more." (Jennifer, 20, white female)

By the end of the course all of the students expressed positions that home life and parenting are among the most, if not the most, influential variables affecting student performance. What schools could realistically do to supplement what parents may or may not be doing at home was a point of contention. However, all of the students felt that schools should work to encourage parental involvement to whatever degree possible.

\section{Theme 2. Home language/ School Language}

In discussions about the academic preparedness of low SES and minority students, the topic of language often arose and was used as a means to discuss how cultural differences between home and school could lead to academic challenges, particularly for students not often exposed to Standard English.

The class acknowledged that the expected (and valued) language of school is polished Standard English, and that the vast majority of low SES students grow up in households where it is often not spoken. Consistent with the conclusions of many linguistic researchers (Preece, 2010) the professor made certain to state that Standard English was not inherently superior to other languages or forms of English, but rather that it is what is most valued in the academic setting (Author, 2009). Furthermore, language was our primarily example used when attempting to illustrate the concept of cultural discontinuity. The students' home language and school language may be vastly different, and it is that difference that creates the issue, not any inherent superiority or inferiority in either language. 
To help frame the discussion, the following essential question was utilized in a writing assignment: What is $a$ school's responsibility in terms of addressing the language skills and needs of low SES students?

The vast majority of students agreed on what the goals of schools should be in this area, but disagreed on how to achieve these goals. Most agreed that the schools had an obligation to prepare students for careers and/or college, and that preparation for these areas would require ensuring that students could speak, read, and write in what they often referred to as "good" or "correct" or "proper" English. However, disagreement centered on the degree to which, if at all, schools should ensure competency in the students' home language, and whether or not schools should encourage students to use their first languages while trying to master Standard English.

Many of the students (about half) supported and encouraged bilingual education and intensive ESL (English as a Second Language) instruction, arguing that it was the school's responsibility to make students feel comfortable and welcome, and to keep them from falling behind. They believed Standard English could be taught once students felt emotionally safe and connected with their school communities and teachers.

Lourdes sums this view up well:

"I don't think most people know how hard it is to be an immigrant and not know the language. There is a huge emotional price to pay. Part of that price is that you feel dumb because you don't know what the teacher is saying, and that adds to the frustration. Just because you don't know the language does not mean you are dumb.... before you can really teach these students they have to feel smart, like that the skills they have count and matter. Once you get to that point, then you can focus in more on the academic stuff" (Lourdes, 21, Hispanic female)

The other half of the group felt very different. They acknowledged the importance of the affective concerns Lourdes mentions, but expressed that providing instruction in students' native languages could end up doing a disservice to them, because it delays and retards their mastering English, which is a prerequisite to excelling in school. Interestingly, whether or not a student in the study was a bilingual or ESL student him or herself did not appear to correlate with which side of the debate they supported. Angela's description of her own experiences is telling:

"Nobody knows better than me what it means to have to try and go to school in another country with a different language. I came here from the DR (Dominican Republic) when I was nine and didn't really speak any English. ... when I first started in school here they put me in a bilingual program, and I remember I was at home and my mom asked about my homework and I showed her these math word problems and they were in Spanish and she almost freaked out. She was like, 'I didn't come all this way to give you a better life so you could practice Spanish. You need English to succeed here, we speak enough Spanish at home.' The next day she went to the school and told them- in Spanish- to take me out of any of the bilingual stuff. ...by that summer my English was almost as good as my Spanish, and my written English was even better." (Angela, 20, Hispanic female)

Issues around slang (Non-Standard English) and Standard English also emerged throughout the classroom discourse. One of the challenges in exploring these issues was that while students could easily identify many types of slang and some Non-Standard English, they were not always fully aware of what was and was not Standard English themselves. Thus discussing what schools' responsibilities may be in this area was difficult. Ultimately, the discussion focused on blatant examples of Non-Standard English and what, if anything, schools should be doing to address them.

Here again there was consensus that schools and teachers had a responsibility to teach Standard English in order to help close the achievement gap, but the best means to that end was debated. The majority of the students, approximately 70 percent, took a somewhat conservative approach to Non-Standard English and expressed their beliefs that schools should essentially have a zero tolerance policy for slang and/or Non-Standard English. The comment below captures the "zero tolerance" stance:

"If teachers don't come down hard on correct grammar and speech, then who will? Lots of times kids are surrounded with slang, be it in rap songs, with their friends, in the neighborhood, all that. School should be the one place where it's not tolerated...that's part of the teacher's job. Some teachers think they are being cool or whatever by talking slang and not making a big deal out of it, but what happens at a job interview? Then that student does not get the job which contributes to unemployment. It's all connected." (James, 20, African American male)

There was however, a numerical minority of students, approximately 30 percent, who took a more nuanced approach to this language debate. They often focused on the fact that Non-Standard English is often the language of home and 
of the children's parents, and as such it should be treated delicately and with respect. These students agreed that teachers must teach Standard English, but they were not against skillfully using Non-Standard English in the process.

"I don't think you can just tell someone to stop using their home language, if you think about it, it's an insult in a way. Especially if it's the language their parents use. If I as a teacher criticize a student's language, then I am criticizing the student and his community and his family....Just like if they speak a foreign language at home, we shouldn't just tell them to forget it. I'd be like someone telling me to stop speaking Tagalog....Teachers should point out that there is a time and a place for different languages and help students know when to use which." (Teresa, 24, Asian female)

"I remember I had a high school English teacher who let us switch back and forth between slang and proper English and it was one of the most fun assignments we did. She let us write dialogues of people from different backgrounds, so that then we had to match how they spoke with who they were...like a business executive would be talking to a bike messenger... it made us see the different times and places when it was okay to speak different types of English." (Manuel, Hispanic male, 20).

\section{Theme 3. Bicultural Teachers}

Another major theme that continually reared its head in discussion about the achievement gap and under-achieving urban schools is the degree to which the teachers understand and/or can relate to the children they are serving. The students in the study were well aware of the discrepancy between the typical teacher and her students. This reality creates context for the potential of severe cultural discontinuity.

Questions regarding how effectively teachers who have limited understandings of their students' backgrounds and home lives can teach received much discussion. Terms such as "bicultural teachers" and "cultural discontinuity" were new to the students, but the concepts were well recognized and elicited a great deal of response. Many students could describe teachers at both ends of the bicultural spectrum- those very much in tune with student culture as well as those who had little understanding of what their students experienced outside of their classrooms. Bicultural teachers are those who are significantly knowledgeable about and aware of the students' home lives (e.g. language, ethnic/cultural traditions, economic realities, popular culture consumption) while simultaneously being able to utilize that knowledge to help students acquire the skills necessary to excel in the academic milieu (e.g. Standard English, academic skills, preparation for college). Truly bicultural teachers are rare, but often extremely effective (Fitts \& Weisman, 2010). Theoretically, teachers highly adept in both areas are better suited to be "cultural glue" or "cultural translators", able to help connect the academic requirements to the students' non-school lives.

The vast majority of the students 58 percent? 58/62? thought being bicultural was an asset for teachers, and about 60 percent thought it absolutely essential to student achievement.

For those who did find it crucial, the two areas most impacted by bicultural teachers were helping students feel emotionally validated and comfortable in the classroom, and the challenge of making academic standards and curriculum relevant and meaningful. Joell's description of one of his favorite middle school teachers demonstrated how being bicultural could serve to create an emotionally comforting environment for students often coming from marginalized backgrounds:

"Ms. Perez was really critical for me because I had her for English language arts at a point when I really could have gone either way... I was struggling with confidence with my English and I was starting to doubt if I'd be able to graduate from high school, forget about college...she (Ms. Perez) saw where I was and knew it was not about me being smart enough or anything, but that my language skills, or actually my insecurity about my English, was what was holding me back...at one point three of our teachers had us do oral presentations and I refused.. the two others just failed me, but Ms. Perez understood what the issue was because she went through similar stuff when she was young, so she talked to me and let me do the presentation on video instead of in front of the class...none of the other teachers saw me like she did." (Joell, Hispanic male, age 20)

Joell's anecdote provides a stark example of how deep and personal familiarity with a student's background can lead to sensitive and effective interventions that less bicultural teachers may not even consider, let alone enact.

Other students talked more about biculturalism in terms of educators' potential to inspire and serve as role models. In discussing their previous teachers who served to encourage and motivate, they talked in terms of the individual's ability to connect with them which consequently reinforced the validity of their messages. 
Shantel talked about a young teacher she had for a high school psychology class and how that teacher's familiarity with Shantel's background helped serve as motivation:

"Even though Ms. Carcetti was white, she grew up real similar to me in a lot of ways, she was into hip hop and went to some of the clubs in the City we went to...she didn't really know her father and her mom was on welfare on and off, but she didn't let those things keep her from going to college and getting her degree. She would constantly talk about how she used her experiences to make her strong, that they allowed her to understand and see things others would miss....she made college life see like something actually doable" (Shantel, African American female, 21)

\section{Theme 4. Anti-Intellectual School Climates}

Over $2 / 3$ of the students (42/62) reflected on their middle and high school years and discussed classroom environments that were often chaotic and where attempts to excel in school (e.g.. doing homework, asking questions, bringing home books) were met with derision and often outright contempt. These sorts of extremely negative reflections on urban schools by urban students has been well documented (Alonso, 2009), but is often absent in discussion of the achievement gap. The class came to refer to these types of attitudes and behaviors as indicative of "anti-intellectualism" and cited it as a key cause of the achievement gap.

Experiences of discouragement toward anything associated with formal academics was particularly virulent for the African American and Hispanic students, who sometimes come from cultures where to excel in school carries with it a sense of "selling-out" or "acting-white." During the class the writings of John Ogbu (1994) were read and discussed. Ogbu's work talks about attitudinal differences between what he refers to as "voluntary" vs "involuntary" minorities, and posits that those who have been colonized and/or enslaved (e.g. African Americans) are "involuntary" and tend to distrust and thus reject government's formal education. He contrasts this with the attitudes of those who have immigrated by choice (aka "voluntaries") who tend to embrace schooling willingly as a means of taking advantage of new found opportunities for social advancement.

Ogbu's work is closely related to other research documenting the experiences of minority students being accused of being "race traders" if they spoke Standard English or excelled in school (Tyson, 2011). It is thought that fears of being perceived in these ways causes a reluctance toward achieving academically, and reduces the amount of effort put forth toward formal education.

While the ethnic minority students in the class were most vocal about this issue, to a lesser extent white students reported their own versions of ant- intellectualism, most commonly being referred to as a "nerd" or "geek" because they appeared academically minded. Perhaps not surprisingly, male students were more than twice as likely to have experienced such ridicule.

William's reflection on his eighth grade language arts class captures the essence of the anti-intellectualism that many students of color in particular experience in school:

"There was so little involvement and participation in my classes in middle and high school. It was all about trying to be cool, to talk to girls, to be tough, and doing good in school was seen as the opposite of that. .. I was a pretty good student, but it's like I had to keep that undercover or I'd be made fun of....I remember in eighth grade it was the day before a big vocabulary test and the teacher was trying to review what was going to be on it, and everyone was fooling around, laughing, and interrupting her, and I really wanted to hear so I'd know what to study. So I turned around, I was like "guys, shut up I want to hear this!" and they cracked up laughing at me. They thought it was crazy, like a joke that I wanted to actually listen...It really is tough for a kid who is studious, not only does he not get support, he gets made fun of." (William, African American male, 23)

The students in the study repeatedly talked about the need to create classroom environments and peer groups that supported academic attitudes and behaviors. However, there were significant differences regarding the best way achieve this goal.

Most of the students' suggestions could be placed in one of two categories. The first was essentially to make school "cool" by making it interesting and relevant. The second involved separating and or suspending/expelling those students who "contaminated" the learning environment so that the others could excel.

Most of the students, about 40 percent, believed in the efficacy of the first category, and discussed ways of making school something students would be drawn to and that they would want to embrace. These students made suggestions such as more culturally relevant curricula, more hands on learning, more bicultural and male teachers, 
more vocational programs, and more focus on historical/modern figures of color who have utilized education as a means of success.

Other students ascribed to a "greater good" philosophy, and believed it was unfair for an entire class to devolve into chaos and anti-intellectualism simply because a few students were unable or unwilling to behave in ways conducive to academic success. Mariposa's impassioned plea captures much of what many of these students reported:

"I know it sounds harsh and unfeeling, but I remember what it was like to try, to want to do well in school, and to have the same two or three people constantly messing everything up. When I was younger I didn't care so much, but in high school when I was trying to get into a good college it was stressful and it was unfair. I'd be like, "Why are you even here if you don't want to learn?" and they'd just make a joke or whatever...I'm not saying kick out every kid who misbehaves, but if someone is continually disrupting the whole class and they have been warned a bunch of times, then enough is enough. (Mariposa, Hispanic female, 20)

It should be pointed out that those students opting for more suspensions and expulsions were not necessarily against trying to make school more accessible and fashionable, but they felt there was only so much that could be done in that area, and that ultimately some students may have to be removed in order for the rest to succeed.

All of the students agreed that the school climate could and should be improved if more learning was to take place. There was also consensus that while anti-intellectualism existed everywhere to varying degrees, it was more pronounced and virulent in low-income areas. .

\section{Summary/Implications}

The potential future teachers in this study presented a variety of opinions in their attempts to explain the ongoing academic achievement gap. Despite the similarities of many of their backgrounds, there was a great deal diversity in their views. Additionally, many of their sentiments were infused with passion, in large part because many of these issues were of personal import to them, both as former K-12 students and future teachers.

All of the students identified parenting as a key, and most agreed with research stating that while low SES parents are less likely to be involved in school, it is usually due to a lack of available time rather than interest (Gardner, 2007). However, severe differences as to the extent to which it is or is not the school's responsibility to make up for parental deficiencies were evident. Despite these differences, the students did believe in the efficacy of schools and teachers to help positively alter the life trajectories of low SES students. It is hoped that this sincere belief will translate into high expectations, collaboration with parents, and energized teaching. Institutions preparing teachers, particularly teachers entering urban environments, have an obligation to be honest about the challenges these teachers will face, while simultaneously infusing belief that effective teaching can and will make a difference.

Consistent with research on educator perceptions, most students viewed language gaps between students and schools as major contributors to the achievement gap (Escamilla \&Chavez, 2005). However, a contentious issue was exactly how schools should be addressing the language needs of their students. The debate over how to do this centered on whether or not schools should encourage students to utilize forms of language other than Standard English, and if schools had an obligation to help students maintain their home languages. Regardless of where they came down on these issues, virtually all of the students did express a respect for the students' home languages and acknowledged the cultural discontinuity that is often evident when students come to school from cultures that are vastly different from those that schools value. This should allow these future teachers to more skillfully and effectively negotiate these potential cultural chasms when they enter the profession.

The students believed wholeheartedly in the importance of teacher quality, and focused in on the documented need for bicultural teachers (Darling-Hammond, 2010) and those educators who knew their students well enough to engage in the essential process of making the curriculum more personally meaningful (Howard, Crumptona \& Gregoryb, 2011). The study's sample of students believe that the dearth of these types of teachers could cause alienation among low socioeconomic students, negating their connection to schooling. Many of the participants gave examples of respected bicultural teachers from their own experience, and wanted to follow in their footsteps.

The prospective teachers' belief in the power of quality teachers and schools is noteworthy. We can logically assume that consistent with the Bandura's (1982) work on self-efficacy, the more one believes in the power of schooling, the more effort one will put toward proving that belief. However, it should be noted that one can still run the risk of being too optimistic, expecting massive change and improvement immediately. As it often does, false hope and unrealistic expectations could lead to discouragement, despair, and ultimately abandonment of the profession. 
A good number of study participants reflected on what they viewed as anti-intellectual urban school environments and the challenges these can create for academically minded students. Some students discussed ways of changing how schooling is perceived by k-12 students by altering what is taught and how. Others believed teachers and school officials were obligated to remove recidivist behavioral problems so that the teacher and rest of the class could better learn. As a consequence of these discussions, all of the potential teachers are more aware of the value and importance of school climate and k-12 students' attitudes toward school. It is hoped that this awareness will help them manage difficult students better and create a classroom culture where all students feel comfortable engaging in the learning process.

Documenting attitudes and feelings of future urban teachers regarding these crucial issues provides rare and valuable data that can help ongoing efforts to close the achievement gap. Given how few of these perceptions and dispositions have actually been collected, we are just now scratching the surface as to possible applications. Through increased understanding we can improve everything from teacher recruitment, to professional development, to classroom management and curriculum development. Because they are so close to what is really happening in urban schools, the study's students' unique perspectives can be exceptionally powerful.

\section{References}

Alonso, G. (2009). Our schools suck: students talk back to a segregated nation on the failures of urban education. New York City: New York University Press.

Bandura, A. (1982). Self-efficacy mechanisms and human agency. American Psychologist, 37, 122-148. http://dx.doi.org/10.1037/0003-066X.37.2.122

Banks, J.A. (1991). Multicultural education: Its effects on students' racial and gender attitudes. New York: Macmillan.

Bogdan, R., \& Biklen, S. (1982). Qualitative research for education: An introduction to theory and methods. Boston: Allyn and Bacon.

Borrero, N. (2011). Entering teaching for and with love: Visions of pre-service urban teachers. Journal of Urban Learning, Teaching, and Research, 7, 18-26.

Brown, K.D. (2010). Is this what we want them to say? Examining the tensions in what U.S. preservice teachers say about risk and academic achievement. Teaching and Teacher Education, 26(4), 1077-1087. http://dx.doi.org/10.1016/j.tate.2009.11.003

Gagnona, D.J. \& Mattinglya, M. (2015). Rates of beginning teachers: Examining one indicator of school quality in an equity context. The Journal of Educational Research, 108(3), 226-235. http://dx.doi.org/10.1080/00220671.2013.878300

Collopy, R., Bowman, C., \& Taylor, D. (2012). The Educational achievement gap as a social justice issue for teacher educators. Catholic Education: A Journal of Inquiry and Practice, 16(1), 4-25.

Darling-Hammond, L. (2010). Teacher education and the American future. Journal of Teacher Education, 61, 35-47. http://dx.doi.org/10.1177/0022487109348024

Feistritzer, C.E. (2012). Profile of teachers in the United States, National Center for Educational Information. Washington, DC.

Fitts, S., \& Weisman, E. M. (2010). Exploring questions of social justice in bilingual/bicultural teacher education: Towards a parity of participation. Urban Review: Issues and Ideas in Public Education, 42, 373-393. http://dx.doi.org/10.1007/s11256-009-0139-9

Gardner, D. (2007). Confronting the achievement gap. Phi Delta Kappan, 88, 542-546. http://dx.doi.org/10.1177/003172170708800715

Gomez, M. L., Rodriguez, T. (2011). Imagining the knowledge, strengths, and skills of a Latina prospective teacher. Teacher Education Quarterly, 38, 127-146.

Goldenberg, B.M. (2014). White teachers in urban classrooms: Embracing non-white students' cultural capital for better teaching and learning. Urban Education, 49, 111-144. http://dx.doi.org/10.1177/0042085912472510

Escamilla, K., Chavez, L., \& Vigil, P. (2005). Rethinking the "gap": High-stakes testing and Spanish-speaking students in Colorado. Journal of Teacher Education, 56(2), 132-144. http://dx.doi.org/10.1177/0022487104273791 
Halai, A. (2004). Action research to study classroom impact: is it possible? Educational Action Research, 12(4), 515-534. http://dx.doi.org/10.1080/09650790400200266

Haskins, R., \& Rouse, C. (2013). Time for change: A new federal strategy to prepare disadvantaged students for college. Future of Children, 1-5

Hattie, J. 2009. Visible learning: A Synthesis of over 800 meta-analyses relating to achievement. New York: Routledge.

Haycock, K. (2001). Closing the achievement gap. Educational Leadership, 2, 6-11.

Howard, G.R. (1999). We can't teach what we don't know: White teachers multicultural schools. New York: Teachers College Press.

Howard E., Crumptona, E., \& Gregoryb, A. (2011). "I'm not learning": The role of academic relevancy for low-achieving students. The Journal of Educational Research, 104(1), 42-53. http://dx.doi.org/10.1080/00220670903567398

Ingraham, C. (2014, October 29). Child poverty in the U.S. is among the worst in the developed world, Washington Post, $2 a$.

Ladson-Billings, G. (2006). From the achievement gap to the education debt: Understanding achievement in U.S. schools. Educational Researcher, 35(7), 3-12. http://dx.doi.org/10.3102/0013189x035007003

Lawrence, S. M. (1997). Beyond race awareness. White racial identity and multicultural education. Journal of Teacher Education, 48(2), 108-115. http://dx.doi.org/10.1177/0022487197048002004

Layton, L. (2013, June 27). Academic achievement gap is narrowing, new national data show. The Washington Post, pp 1.

Matias, C.E. \& Liou, D.D. (2015). Tending to the heart of communities of color: Towards critical race teacher activism. Urban Education, (50)5, 601-625. http://dx.doi.org/10.1177/0042085913519338

Matthew, L. (2014, March 15). Higher accountability for college dropout rates. The Huffington Post, 4.

Merseth, K., Sommer, J., \& Dickstein, S. (2008). Bridging worlds: Changes in personal and professional identities of preservice urban teachers. Teacher Education Quarterly, (35)3, 89-108.

Mezirow, J. (2000). Learning as transformation: Critical perspectives on theory in progress. San Francisco: JosseyBass.

Morales, E.E. (2009). Powerful words: Skillful and sensitive empowerment of urban undergraduate pre-service teachers through improvement of Standard English usage. Educational Action Research, 17, 311-326. http://dx.doi.org/10.1080/09650790902914266

Morales, E.E. \& Trotman, F. (2011). A focus on hope: Fifty resilient students speak. Lanham, MD: Rowman Littlefield/University Press of America.

Morrison, J. (2014). Finding traction for social justice practices through the student teaching socialization transition. Journal of Urban Learning, Teaching, and Research, 10, 73-86.

National Center for Educational Statistics. (2013). The condition of education 2013. Washington, DC: National Center for Education Statistics, U.S. Dept. of Education.

National Center for Educational Statistics. (2014). Projections of education statistics to 2022. Washington, DC: National Center for Education Statistics, U.S. Dept. of Education.

Ogbu, J. (1994). Racial stratification in the Unites States: Why inequality persists Teachers College Record, 96(2), 264-298.

Perna, L.W. (2005). The Benefits of higher education: Sex, racial/ethnic, and socioeconomic. Review of Higher Education, 29(1), 23-52. http://dx.doi.org/10.1353/rhe.2005.0073

Preece, S. (2010). Multilingual identities in higher education: Negotiating the "mother tongue", "posh" and "slang." Language and Education, 24, 21-39. http://dx.doi.org/10.1080/09500780903194036

Regan, K., Berkeley, S., \& Ray, S. (2013). Beyond teach and hope: Moving from data to action. Teacher Education Quarterly, 40(3), 123-141. 
Roselle, L. \& Liner, K. (2012). Pre-service teacher vision and urban schools. Journal of Urban Learning, Teaching, and Research, 8, 45-52 2012.

Schratz, M. (1993). Researching while teaching: Promoting reflective professionality in higher education. Educational Action Research, (1)1, 111-133. http://dx.doi.org/10.1080/0965079930010107

Smith, A. (2008). Raising standards in American schools? Problems with improving teacher quality. Teaching and Teacher Education, 24(3), 610-622. http://dx.doi.org/10.1016/j.tate.2007.09.013

Stairs, A. (2008). Preservice teacher learning in an urban school-university partnership: Understanding the complexity of urban teaching. Journal of Urban Learning, Teaching, and Research, 4, 96-108.

Tyson, K. (2011). Integration interrupted: Tracking, black students, and acting white after "Brown." New York: Oxford University Press. http://dx.doi.org/10.1093/acprof:oso/9780199736447.001.0001

Villegas, A.M. (2007). Dispositions in teacher education: a look at social justice. Journal of Teacher Education, 58(5), 370-381. http://dx.doi.org/10.1177/0022487107308419

Williams, S. (2013). Outsider teacher/insider knowledge: Fostering Mohawk cultural competency for non-native teachers. Teacher Education Quarterly, 40, 25-43. 